\title{
PERANCANGAN BUKU INFORMASI CANDI SEWU SEBAGAI KOMPLEKS CANDI BUDDHA TERBESAR DI INDONESIA
}

\author{
Siti Khotami ${ }^{1)}$, Yayah Rukiah ${ }^{2)}$, Herliana Rosalinda ${ }^{3)}$ \\ Program Studi Desain Komunikasi Visual, \\ Fakultas Bahasa dan Seni, Universitas Indraprasta PGRI \\ Jl. Nangka No. 58 C, Tanjung Barat, Jakarta Selatan, 12530, Indonesia \\ Email: sitamisk@gmail.com
}

\begin{abstract}
Abstrak
Penelitian ini bertujuan untuk merancang buku informasi Candi Sewu sebagai kompleks candi Buddha terbesar di Indonesia. Hasil perancangan buku informasi ini bertujuan sebagai bahan pengetahuan tentang warisan budaya bersifat kebendaan untuk pendidikan dan penelitian, agar menambah wawasan dan kecintaan masyarakat tentang kebudayaan. Metode penelitian yang digunakan adalah jenis penelitian kualitatif. Metode kualitatif bertujuan untuk mendeskripsikan fenomena sejarah objek serta aktivitas sosial yang terjadi dalam lingkungan kompleks Candi Sewu karena meneliti tentang arsitektur, relief dan pemugaran. Teknik pengumpulan data berupa studi pustaka (data didapatkan dari buku, jurnal dan online), observasi dan wawancara narasumber dari arkeologi dan BPCB Unit Candi Sewu. Hasil yang dicapai adalah menciptakan media informasi yaitu buku informasi. Buku informasi ini berisi tentang sejarah Candi Sewu berdasarkan Kerajaan Mataramdan Prasasti Manjusrigrha, arsitektur bangunan Kompleks Candi Sewu, mulai dari Candi Induk, Candi Perwara dan Candi Apit, Ragam hias yang ada pada Candi Sewu, terakhir mengenai Pemugaran Candi dan Perawatan Candi.
\end{abstract}

Kata Kunci: Buku Informasi, Candi Sewu, Buddha

\begin{abstract}
The research objective is to design an information book on Sewu Temple as the largest Buddhist temple complex in Indonesia. The results of the design of this information book are aimed at providing knowledge about material cultural heritage for education and research, in order to broaden people's knowledge and love of culture. The research method used is a type of qualitative research. The use of this qualitative method aims to describe the historical phenomena of objects and social activities that occur in the Sewu Temple complex environment because it examines architecture, reliefs and restoration. The data collection techniques were literature study (data obtained from books, journals and online), observation and interviews of resource persons from archeology and the Sewu Temple Unit BPCB. The result achieved is creating information media, namely information books. This information book contains the history of the Sewu Temple based on the Mataram Kingdom and the Manjusrigrha Inscription, the architecture of the Sewu Temple Complex, starting from the Main Temple, Perwara Temple and Apit Temple, the decorations in the Sewu Temple, the last regarding the Temple Restoration and Temple Maintenance.
\end{abstract}

Keywords: Information Book, Sewu Temple, Buddha

Correspondence author: Yayah Rukiah, rukiah.yayah13@gmail.com, Jakarta, Indonesia. 


\section{PENDAHULUAN}

Kekayaan budaya bangsa yang bisa diartikan sebagai warisan budaya merupakan wujud pemikiran dan perilaku kehidupan manusia yang dapat dipahami sejarahnya dan dikembangkan untuk ilmu pengetahuan dan kebudayaan. Candi merupakan warisan budaya bersifat kebendaan, bisa diartikan sebagai tempat peninggalan bersejarah yang bercorak agama Hindu maupun Buddha.

Kata candi mengacu pada berbagai macam tempat dan fungsi bangunan. Berdasarkan wawancara dengan Deny Wahju Hidayat selaku KA Unit Candi Sewu (19 Desember 2019) diketahui bahwa candi ada dua, yang pertama candi yang berada di puncak perbukitan seperti Candi Gedong Songo, Candi Cetho, Candi Sukuh dan sebagainya. Itu untuk pertapaan, yang kedua candi yang berada di dataran rendah, seperti Candi Sewu, Candi Prambanan, Candi Plaosan dan sebagainya. Itu sebagai mercusuar kerajaan. Berdasarkan fungsi bangunan, candi dapat berfungsi sebagai makam atau peribadatan seperti Candi Sewu.

Candi Sewu merupakan situs kompleks candi Buddha yang memiliki 249 candi yang terdiri dari 1 Candi Induk, 8 Candi Apit dan 240 Candi Perwara. Namun bangunan Candi Perwara yang berdiri utuh saat ini baru 16 Candi Perwara (wawancara dengan Deny Wahju Hidayat selaku KA Unit Candi Sewu 19 Desember 2019). Candi Sewu bercorak agama Buddha, hal itu berdasarkan adanya stupa dan diperjelas dalam Prasasti Manjusrigrha. Prasasti Manjusrigrha menjelaskan Candi Sewu berlatar belakang agama Buddha dengan tokoh utama Manjusri. Dalam diri Manjusri tersembunyi Buddha, Dharma dan Sangha.

Kompleks Candi Sewu terletak di Desa Bugisan, Kecamatan Prambanan, Kabupaten Klaten, Provinsi Jawa Tengah. Candi Sewu ini termasuk kedalam kawasan Prambanan dan berada di sebelah utara Candi Prambanan. Luas situs Komplek Candi Sewu sekitar 31.720,5 m². Komplek Candi Sewu memiliki 4 pintu gerbang menuju pelataran luar yang dijaga oleh sepasang Arca Dwarapala. Dari tiap pintu gerbang tersebut dapat terlihat susunan Candi Apit dan Candi Perwara yang mengelilingi Candi Induk. Susunan denah candi tersebut menunjukkan konsep kosmologi Buddha (Murdihastomo, 2018: 69).

Ragam hias pada bangunan Kompleks Candi Sewu dalam bentuk relief ini bersifat relief non cerita. Relief non cerita yaitu relief yang motif-motifnyahanya sebagai pemanis, tanpa makna, ada pula motif khusus yang mengandung arti simbolis menurut latar belakang keagamaan candi tersebut (Istari, 2015: 4). Dengan begitu Kompleks Candi Sewu hanya dihiasi dengan ragam hias tumbuh-tumbuhan, ragam hias geometris dan ragam hias kombinasi.

Walaupun Kompleks Candi Sewu masih dibilang candi yang belum sempurna dikarenakan banyak candi yang harus dilakukan pemugaran, kemegahan dari Kompleks Candi Sewu ini tetap bisa dirasakan saat melihat keseluruhan candi dari pintu gerbang pelataran. Banyaknya bangunan candi dengan susunan yang geometris ini memberikan keunikan tersendiri dari Candi Sewu yang tidak dimiliki oleh candi lain. Menurut Rahadian, potensi Candi Sewu terdapat nilai-nilai berupa seharah dan budaya. Adapun nilai-nilai budaya dan sejarah pada Candi Sewu terdiri dari pengetahuan sejarah perjalanan agama Budha, serta jenis arsitektur dan karakter/ identitas dari budaya awal di Pulau Jawa (Infantyo et al., 2017: 25). Oleh karena itu pula, Kompleks Candi Sewu merupakan Kompleks Candi Buddha terbesar di Indonesia. Candi Sewu ini juga sudah ditetapkan sebagai warisan dunia dengan nama Prambanan Temple Compounds oleh UNESCO World HeritageCommittee pada tahun 1991 dengan No. C. 642 yang meliputi Candi Prambanan, Candi Sewu, Candi Bubrah dan Candi Lumbung.

Tetapi, walaupun Candi Sewu sudah diakui sebagai warisan dunia, eksistensi Kompleks Candi Sewu belum terlalu diketahui oleh masyarakat. Kendala lokasi dan transportasi kawasan Prambanan yang cukup jauh menuju Candi Sewu membuat masyarakat tidak terlalu ingin mengunjunginya. Dan beberapa dari masyarakat juga masih berasumsi bahwa Candi Sewu merupakan bagian dari Candi Prambanan. Informasi mengenai Candi Sewu pun belum bisa di akses secara mudah dan menyeluruh, kebanyakan informasihanya mengenai pemugarannya saja.

Dengan begitu diperlukannya media promosi dan informasi yang lengkap dan menarik mengenai Kompleks Candi Sewu untuk masyarakat. Sehingga masyarakat bisa memahami 
sejarah dan mengembangkan pengetahuannya untuk melestarikan dan memanfaatkan Kompleks Candi Sewu secara tepat dalam rangka memajukan kebudayaan nasional.

\section{METODE PENELITIAN}

Metode penelitian pada dasarnya merupakan cara ilmiah untuk mendapatkan data dengan tujuan dan kegunaan tertentu. Berdasarkan hal tersebut terdapat empat kata kunci yang perlu diperhatikan yaitu, cara ilmiah, data, tujuan dan kegunaan. Sugiyono mendefinisikan metode penelitian adalah cara ilmiah untuk mendapatkan data dengan tujuan dan kegunaan tertentu. (Sugiyono, 2012:3).

Metode penelitian yang digunakan adalah metode kualitatif. Penelitian kualitatif adalah penelitian yang pemecahan masalahnya dengan menggunakan data empiris (Mahsyuri \& Zainuddin, 2008: 13). Digunakannya metode kualitatif ini bertujuan untuk mendeskripsikan fenomena sejarah objek serta aktivitas sosial yang terjadi dalam lingkungan kompleks Candi Sewu. Data yang didapat adalah faktual dan aktual dalam mencapai tujuan penelitian, yaitu merancang buku informasi Candi Sewusebagai Candi Buddha terbesar di Indonesia.

Studi Pustaka menurut Sugiyono, studi kepustakaan berkaitan dengan kajian teoretis dan referensi lain yang berkaitan dengan nilai, budaya, norma yang berkembang pada situasi sosial yang diteliti, selain itu studi kepustakaan sangat penting dalam melakukan penelitian, hal ini dikarenakan penelitian membutuhkan literatur-literatur ilmiah yangmemiliki data yang relevan terhadap permasalahan yang akan diteliti dengan melakukan studi pustaka berupa buku, jurnal, skripsi dan artikel serta situs web resmi. (Sugiyono, 2012: 291).

Observasi atau pengamatan adalah kemampuan seseorang untuk menggunakan pengamatannya melalui hasil kerja panca indra mata serta dibantu dengan panca indra lainnya (Bungin, 2001: 142). Maka metode observasi ini merupakan metode pengumpulan data yang digunakan untukmenghimpun data penelitian melalui pengamatan dan pengindraan. Observasi dilakukan di Kompleks Candi Sewu untuk mengetahui informasi tentang sejarah, kondisi dan fakta - fakta mengenai Candi Sewu serta jenis media yang berkaitan dan dibutuhkan dengan Candi Sewutujuannya untuk mendapatkan referensi dalam perancangan media.

Wawancara merupakan alat rechecking atau pembuktian terhadap informasi dan keterangan yang diperoleh sebelumnya. Wawancara ini dilakukan dengan menemui narasumber Darsono selaku anggota Badan Pelestarian Cagar Budaya Jawa Tengah bagian Administrasi Pemugaran untuk mendapatkan data yang berkaitan dengan Candi Sewu, selain juga wawancara dengan Agus Kuncoro selaku anggota Balai Pelestarian Cagar Budaya Jawa Tengah bagian Lapangan Pemugaran untuk mendapatkan informasi mengenai keadaan bangunan dan pemugaran Candi Sewu.

\section{HASIL DAN PEMBAHASAN}

Candi Sewu merupakan candi Buddha yang letaknya berada di sebelah utara Candi Prambanan dan termasuk ke dalam kawasan wisata Candi Prambanan. Kompleks Candi Sewu ini terletak di Desa Bugisan, Kecamatan Prambanan, Kabupaten Klaten, Provinsi Jawa Tengah. Berdasarkan wawancara dengan Darsono selaku anggota BPCB Jawa Tengah bagian Administrasi Pemugaran (04 Mei 2019) diketahui bahwa nama asli Candi Sewu adalah Candi Manjusrigrha. Nama Candi Sewu tersebut berasal dari cerita lisan para warga sekitar yang melihat banyaknya candi yang jumlahnya seperti ada seribu.

\section{Sejarah Candi Sewu sebagai Candi Buddha}

Nama Manjusrigrha diketahui dengan adanya Prasasti Manjusrigrhayang ditemukan pada tahun 1960 di Candi Perwara nomor 202 di situs Candi Sewu. Batu tertulis yang memuat prasasti dalam bahasa Melayu Kuno dan berangka tahun 792 yang menyebut diadakannya perluasan atau perindahan bangunan (Dumacay, 2018: 15).

Candi Sewu dibangun oleh Sri Maharaja Rakai Panangkaran, yang merupakan seorang raja kedua dari kerajaan Mataram Kuno. Candi Sewudiperkirakan didirikan pada abad ke 8 masa dinasti Syailendra. Kerajaan Mataram Kuno memiliki 3 dinasti yaitu, dinasti Sanjaya, dinasti 
Syailendra dan Dinasti Isana. Dinasti Sanjaya merupakan pemeluk agama Hindu beraliran Syiwa sedangkan dinasti Syailendra merupakan pengikutBuddha Mahayana dan dinasti Isana merupakan dinasti baru yang didirikan oleh Mpu Sindok.

Awalnya raja pertama Kerajaan Mataram Kuno yaitu Sanjaya menganut agama Hindu, karena Beliau merupakan pendiri Wangsa Sanjaya. Setelah Sanjaya wafat, kekuasaan Kerajaan Mataram Kuno di gantikan oleh anaknya yaitu Sri Maharaja Rakai Panangkaran. Rakai Panangkaran berpindah agama Buddha beraliran Mahayana. Saat itulah dinasti Syailendra berkuasa. Rakai Panangkaran berkuasa tahun pada 746- 784 Masehi. Perkembangan dinasti ini menyingkirkan kedudukan dinasti Sanjaya. Di masa kepemimpinan Rakai Panangkaran Kerajaan Mataram Kuno mengalami perkembangan yang progresif. Untuk menunjukan eksistensi akan kepemimpinannya semasa berkuasa, Rakai Panangkaran membangun beberapa candi, seperti Candi Sewu, Candi Kalasan, Candi Plaosan dan Candi Borobudur. Candi Sewu selesai ketika Rakai Panangkaran sudah wafat sehingga ia tidak dapat menikmati keagungan Candi Sewu.

\section{Konsep Dasar Perancangan}

\section{Konsep Media}

1. Judul buku informasi yaitu Candi Sewu Simbol Toleransi Agama

2. Bentuk dari buku informasi ini adalah potrait ukuran 20x25 cm.

3. Isi buku informasi ini terdiri dari:
a. Pendahuluan
b. Bab I Sejarah Candi Sewu sebagai Candi Buddha
c. Bab II Arsitektur di Kompleks Candi Sewu
d. Bab III Pemugaran Kompleks Candi Sewu
e. Bab IV Kesimpulan

Ilustrasi yang akan dipakai berupa foto - foto yang di dokumentasikan saat melakukan observasi. Layout yang digunakan bertema simple, minimalis dan modern.

\section{Konsep Visual}

1. Mind Mapping

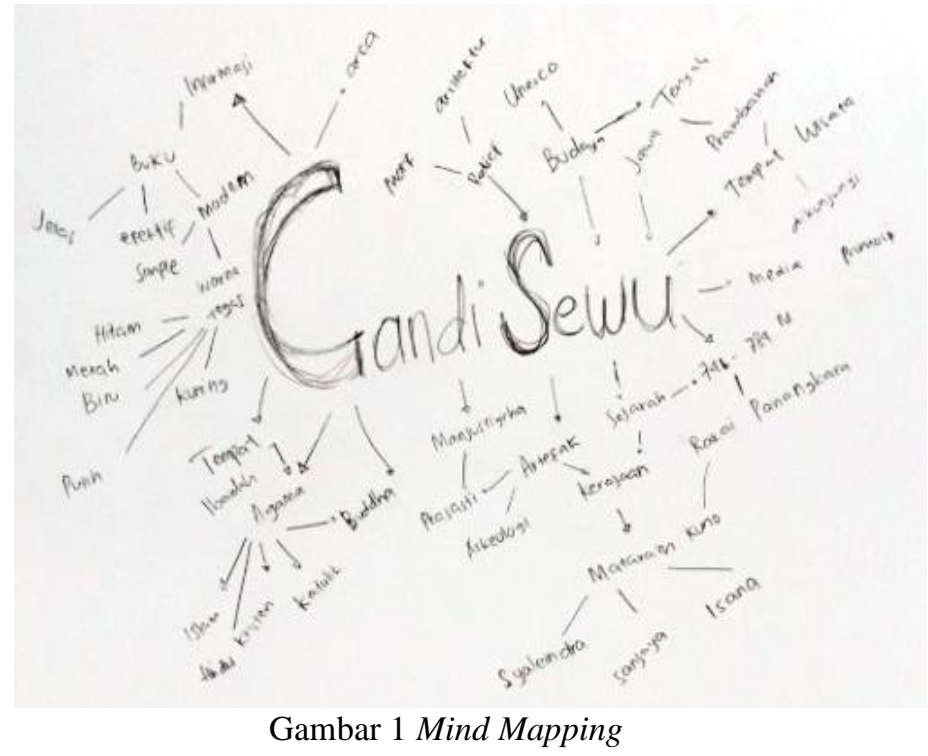




\section{Mood Board}

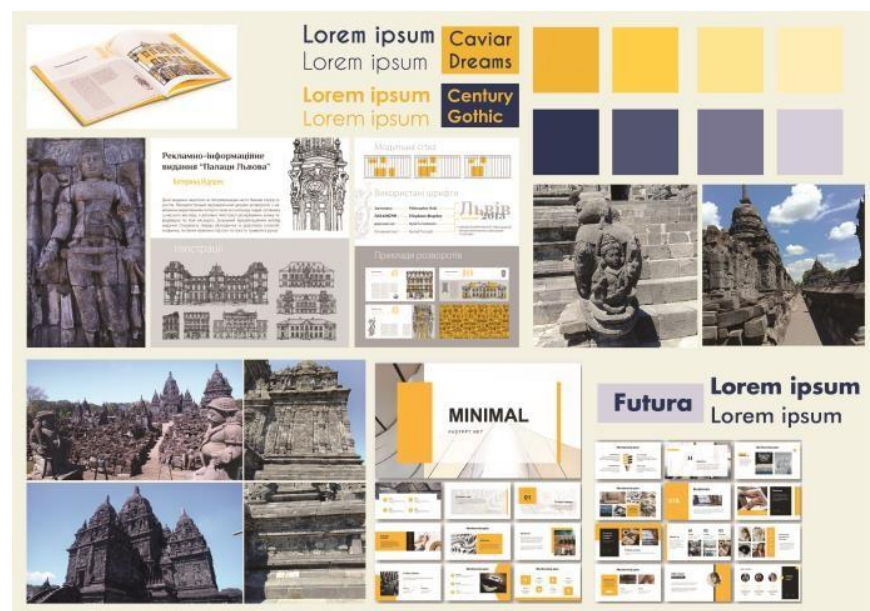

Gambar 2 Mood Board

\section{Gaya Ilustrasi}

Di dalam penelitian perancangan media buku informasi akan menggunakan elemen Ilustrasi berupa, foto, vektor, infographic (berupa peta \& diagram), garis, kotak/ border dan point/ bullets. Elemen ilustrasi foto yang akan banyak digunakan dalam perancangan media buku informasi ini.

\section{Skema Warna}

Warna yang digunakan dominan warna biru tua, kuning dan putih.Warna ini dipilih berdasarkan makna yang berkaitan dengan judul dan target khalayak dari media buku informasi yang dirancang dalam penelitian ini.

Menurut Molly E. Holzchang seorang pakar tentang warna dan tulisannya Creating Color Scheme, menyatakan bahwa warna biru juga mampu menimbulkan respons psikologi yaitu kepercayaan, konservatif, keamanan dan kebersihan (Kusrianto, 2009: 47).

Warna kuning adalah warna matahari, sumber energi dan sumber cahaya alam di bumi. Sama halnya dengan agama, agama bisa diartikan sebagai sumber cahaya (pencerahan) untuk manusia dalam menjalankan hidup. Secara psikologi kuning dikaitkan dengan kecerdasan, ide baru serta kepercayaan terhadap potensi diri. Dameria mengemukakan bahwa warna kuning adalahwarna yang sangat positif sehingga dapat dipakai untuk memberi semangat. Warna kuning pun lebih eye catching untuk penjualan, sehingga dapat menarik perhatian mata pembaca dari kejauhan. (Dameria, 2007: 34).

Warna putih mempunyai arti bersih dan suci. Warna ini memberi kesan kebebasan dan keterbukaan. Warna putih ini digunakan karena konsep media buku informasi ini minimalis dan juga agar kombinasiantara warna kuning dan biru ini seimbang.

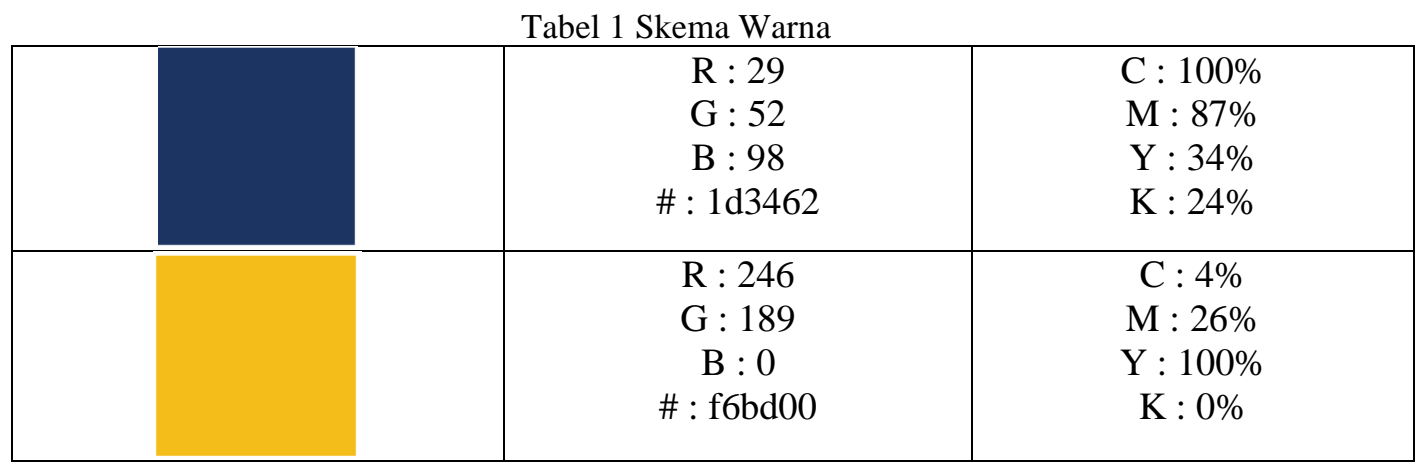




\begin{tabular}{|l|l|l|}
\hline & $\mathrm{R}: 255$ & $\mathrm{C}: 0 \%$ \\
& $\mathrm{G}: 255$ & $\mathrm{M}: 0 \%$ \\
& $\mathrm{~B}: 255$ & $\mathrm{Y}: 0 \%$ \\
& $\mathrm{H}: \mathrm{ffffff}$ & $\mathrm{K}: 0 \%$ \\
\hline
\end{tabular}

5. Pemilihan Huruf

Dalam perancangan buku informasi ini, menggunakan jenis tipografi San Serif. Untuk cover buku menggunakan font CaviarDreams. Untuk isi buku, menggunakan font Futura untuk judul dan headline, sedangkan body text, footnote dan sebagainya. Menggunakan nama font Century Gothic sesuai dengan konsep dankhalayak yang di targetkan.

\section{A B C D E F G H I K L M N O P QR ST U V W X Y Z \\ $a b c d e f g h i j k I m n \circ p$ qrstuvwxyz \\ 1234567890 \\ Caviar Dream}

Gambar 3 Jenis Font pada Cover Buku

\section{A B C DEF G H I KL M N O P Q R S T U V X Y Z}

a b c d e f g h i j k I m n o p qrstuvw $x y z$

\section{0}

Futura

Gambar 4 Jenis Font pada Judul, Bab dan Headline

\section{A B C D E F G I J K L M N O P Q R S T U V W X Y Z}

$a b c d e f g h i j k I m n o p$

arstuvwxyz

\section{0}

Century Gothic

Gambar 5 Jenis Font pada isi buku 


\section{Proses Perancangan}

Dalam sebuah proses perancangan dilakukan secara bertahap sesuai dengan tahapan yang telah ditentukan melalui kesepakatan, untuk mendapatkan hasil rancangan yang menarik dan efektif diterapkan 2 tahap proses yaitu:

Proses ini meliputi proses sketsa manual tata letak (Layout) dan Alternatif desain digital.

Sketsa Manual Tata Letak

Dalam perancangan buku informasi tahap awal yang dipikirkan adalahmembuat sketsa manual tata letak. Sketsa manual tata letak terdiri atas sketsa desain sampul, sketsa tata letak halaman bab, sketsa tata letak halaman isi yang dibuat dalam beberapa alternatif.

\section{Sketsa Desain Sampul}

Ada dua alternatif sketsa desain sampul. Kedua dari sketsa desainsampul depan akan menggunakan ilustrasi Foto dari Candi Sewu.
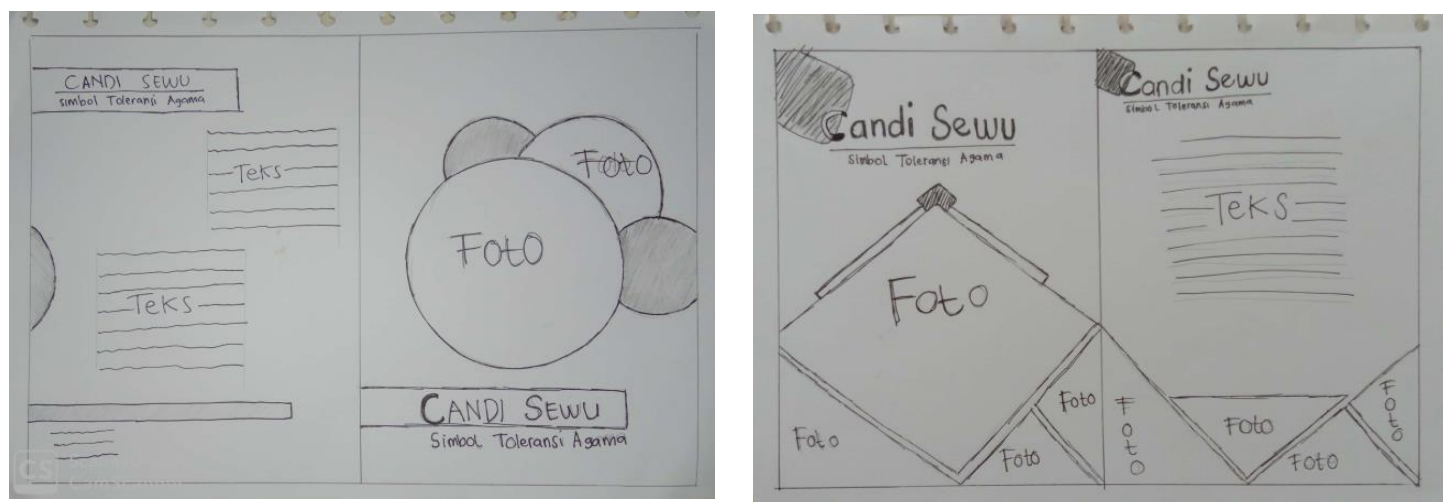

Gambar 6 Sketsa desain sampul alternatif 1 dan 2

\section{Sketsa Desain Bagian Bab} highlight.

Sketsa desain bagian bab dibuat simple dan clearly agar lebihmudah terbaca dan ter-

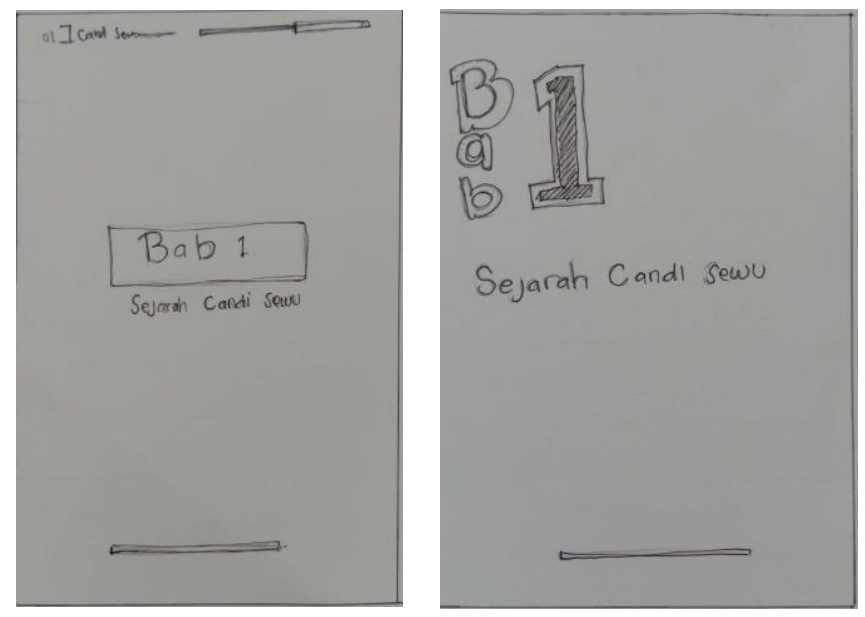

Gambar 7 Sketsa desain bab alternatif 1 dan 2

\section{Sketsa Desain Isi Buku}

Sketsa desain isi buku dibuat dengan 2 alternatif. Sesuai dengan target khalayak, maka sketsa desain isi buku dibuat dengan layout yang simple. Informasi yang di tampilkan juga berupa teks dan foto sebagai pendukung. 

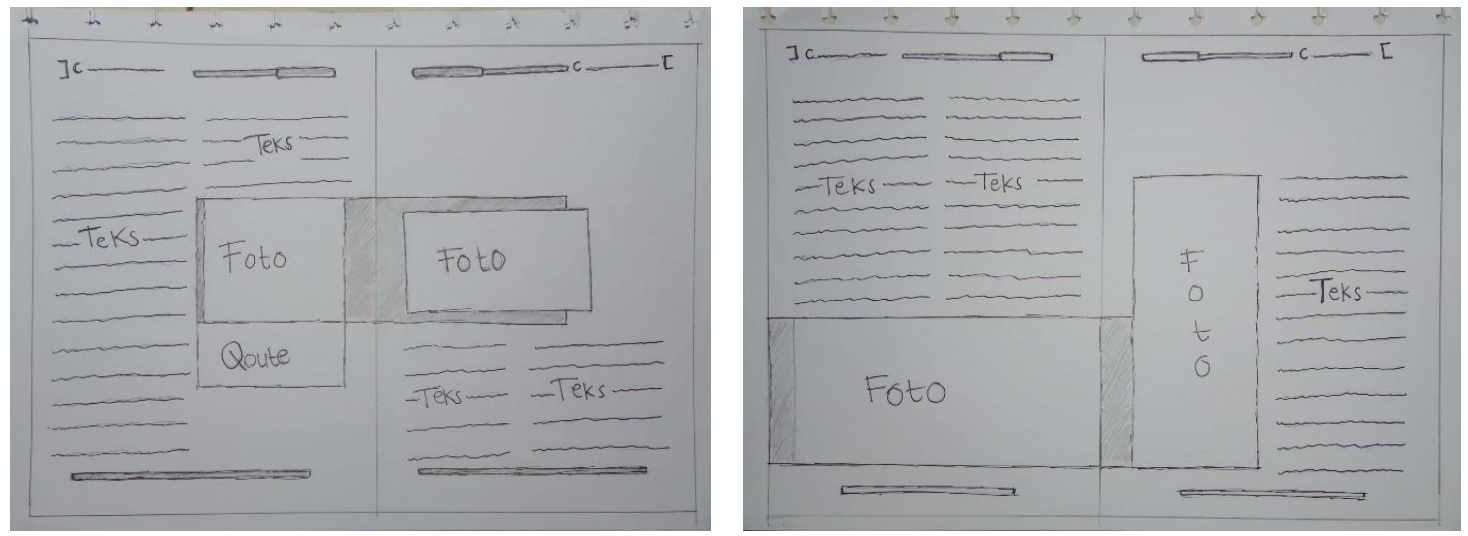

Gambar 8 Sketsa desain halaman isi 1 dan 2 alternatif 1
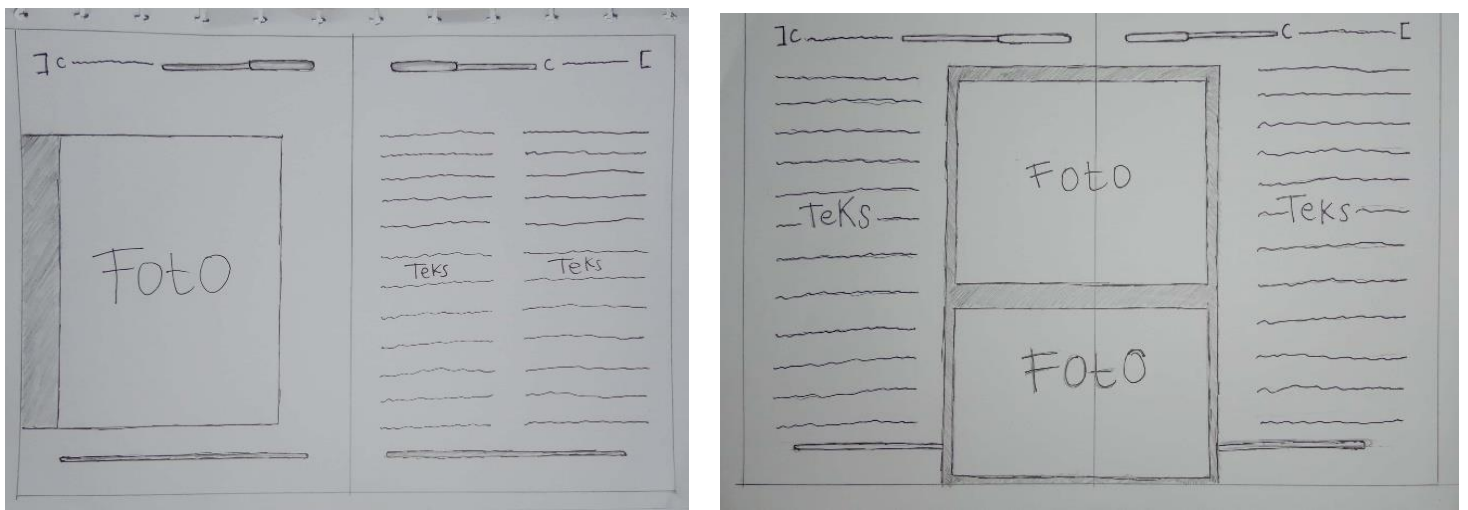

Gambar 9 Sketsa desain halaman isi 1 dan 2 alternatif 2

\section{Alternatif Desain Digital}

Setelah sketsa desain sudah dibuat, tahap selanjutnya yaitu membuat sketsa desain tersebut ke dalam digital menggunakan software Adobe Illustrator. Dengan desain digital ini membuat pemilihan desain alternatiflebih mudah, karena desain sudah full color dan layout terlihat lebih jelas.Alternatif desain digital terdiri atas desain digital sampul, desain digital bagian bab dan desain digital isi buku.

\section{Desain Digital Sampul}

Desain digital sampul ini berdasarkan sketsa kasar yang sudah dibuat sebelumnya dan dikembangkan. Sesuai dengan konsep perancangan yang sudah ada, sampul buku dibuat dengan warna tegas seperti biru dan kuning, dan warna terang (warna putih atau yang mendekati putih). Ilustrasi yang dipakai berupa foto. Desain sampul dirancang simple dan modern karena disesuaikan dengan target khalayak yaitu sekitar 18-25 tahun.
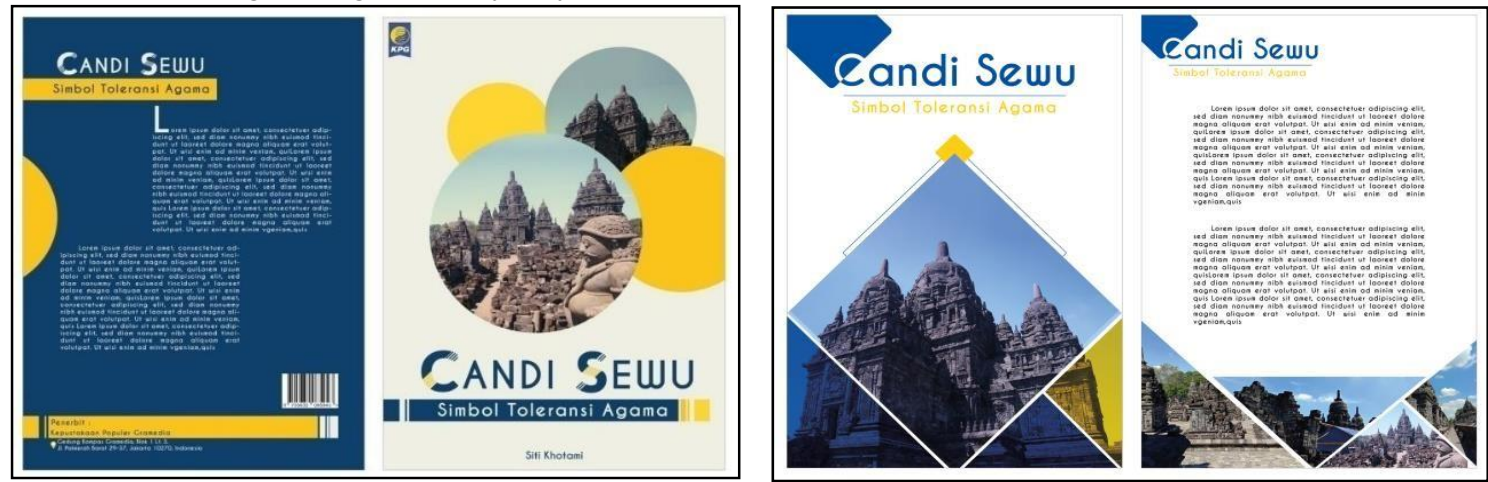

Gambar 10 Desain Digital Sampul Alternatif 1 dan 2 


\section{Desain Digital Bagian Bab}
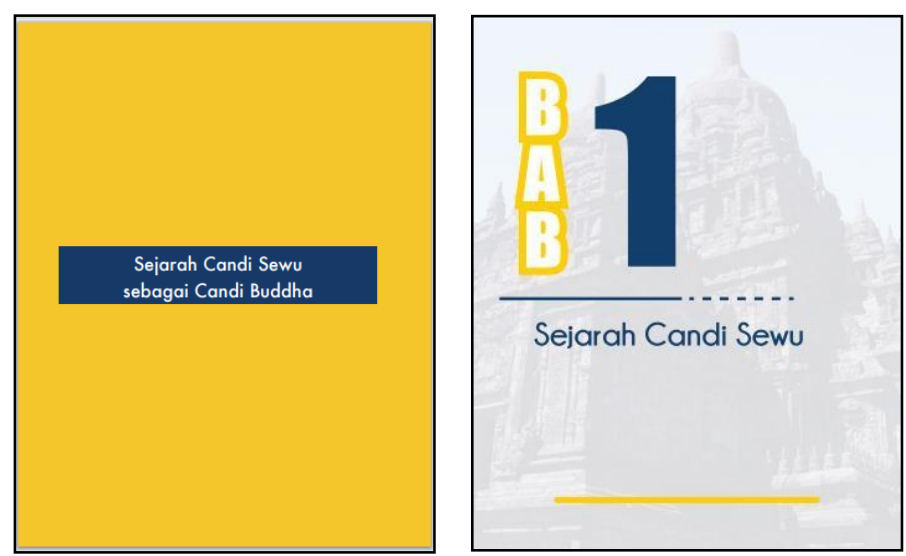

Gambar 11 Desain Digital Bab Alternatif 1 dan 2

\section{Desain Digital Isi Buku}

Alternatif desain isi buku berdasarkan sketsa kasar yang dikembangkan lagi dan disesuaikan dengan materi yang akan disampaikan. Dalam buku informasi ini kemungkinan menggunakan ilustrasi foto dari hasil observasi dan dari sumber lainnya yang digunakan sebagai informasi penunjang materi.
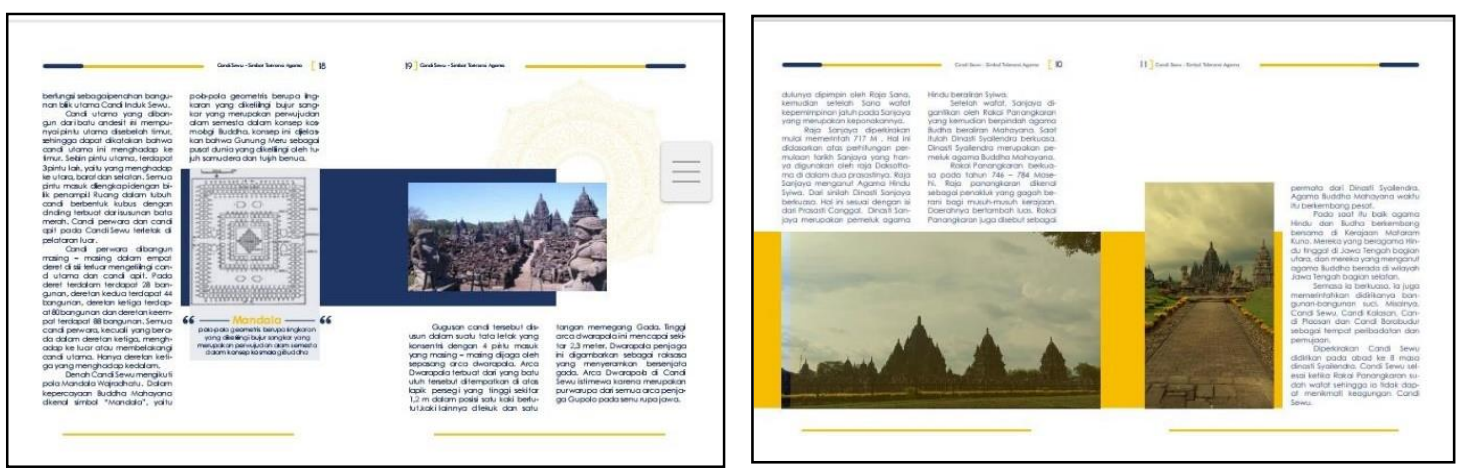

Gambar 12 Desain Digital Isi Buku 1 dan 2 Alternatif 1
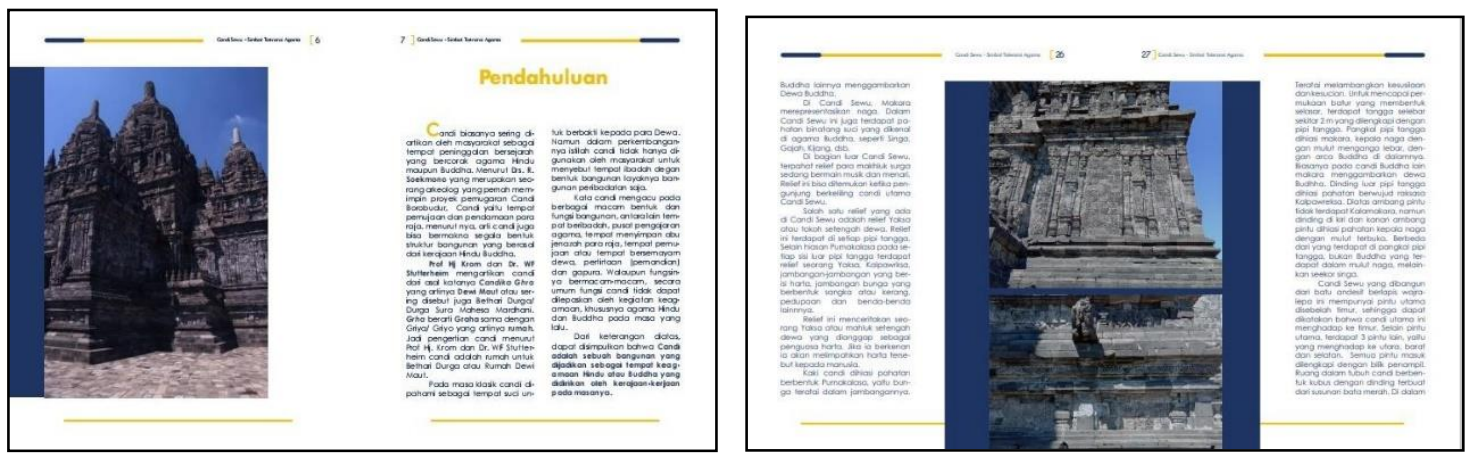

Gambar 13 Desain Digital Isi Buku 1 dan 2 Alternatif 2

\section{Hasil Perancangan}

Hasil perancangan yaitu proses akhir karya yang telah dipilih dan ditentukan desain dan layout nya untuk dijadikan sebuah buku informasi yangberjudul Candi Sewu, Simbol Toleransi Agama. Buku informasi Candi Sewudibuat menggunakan Adobe InDesign dalam menyusun materi isi buku sepertilayout text, gambar dan sebagainya sedangkan untuk Cover buku dibuat menggunakan Adobe Illustrator. Buku informasi Candi Sewu ini akan diterbitkan dan distribusikan ke beberapa perpustakaan, seperti perpustakaan nasional, perpustakaan daerah dan 
perpustakaan perguruan tinggi yang beradadi Pulau Jawa khususnya daerah Yogyakarta. Berikut hasil rancangan buku informasi Candi Sewu:

\section{Sampul Buku}

Hasil akhir desain sampul buku depan dan belakang pada buku informasi Candi Sewu Simbol Toleransi Agama menggunakan warna biru, kuning dan putih. Sampul buku bagian depan memiliki warna dasar putih tulang dan terdapat 2 foto kompleks Candi Sewu dari sudut yang berbeda. Pada kata Candi Sewu menggunakan font figurative. Sampul buku bagian belakang memiliki warna dasar biru tua, dan terdapat 1 paragraf sinopsis buku.

Spesifikasi sampul buku sebagai berikut:

1. Judul buku

: Candi Sewu Simbol Toleransi Agama

2. Nama Penulis

: Siti Khotami

3. Ukuran

: $25 \times 20 \mathrm{~cm}$ potrait

4. Margin Halaman

Atas \& Bawah : $3,5 \mathrm{~cm}$, luar : $2,5 \mathrm{~cm}$ dalam $: 3 \mathrm{~cm}$

5. Jenis Kertas : Cover menggunakan Art Cartoon $310 \mathrm{gr}$,

6. Teknik Cetak : Cover akan dicetak Hard Cover, laminating doff, dan bagian judul Candi Sewu dan lingkaran kuning akan di finishing UV Spot.

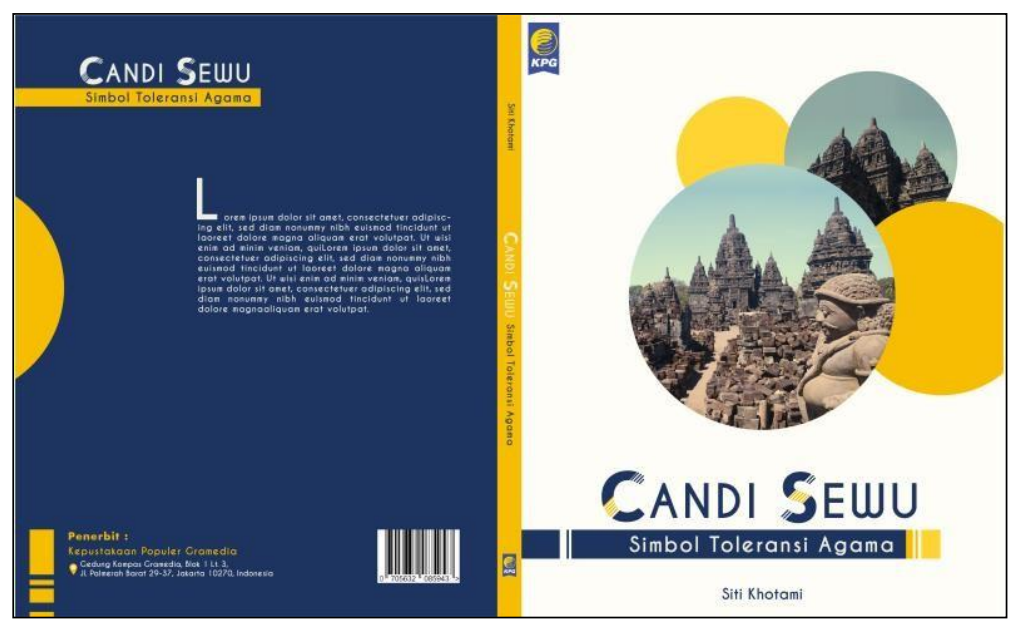

\section{Isi Buku}

Gambar 14 Hasil Rancangan sampul buku

Hasil akhir isi buku terdiri dari beberapa tata letak teks dan gambar yang berbeda. Isi buku terdiri dari 3 macam kolom, 1 kolom, 2 kolom dan 3 kolom agar lebih bervariasi dan tidak membosankan. Warna bagian isi buku ini menggunakan warna kuning, putih dan biru seperti pada sampul buku.

Spesifikasi isi buku sebagai berikut :

1. Ukuran : $25 \times 20 \mathrm{~cm}$ potrait

2. Margin Halaman : Atas \& Bawah : $3,5 \mathrm{~cm}$, luar : $2,5 \mathrm{~cm}$ dalam : $3 \mathrm{~cm}$

3. Jenis Kertas : Matte paper $150 \mathrm{gr}$,

4. Teknik Cetak : Digital Printing

5. Ukuran font : Materi : 10,5 pt. Bab : 26 pt, Sub Bab : 22 pt 


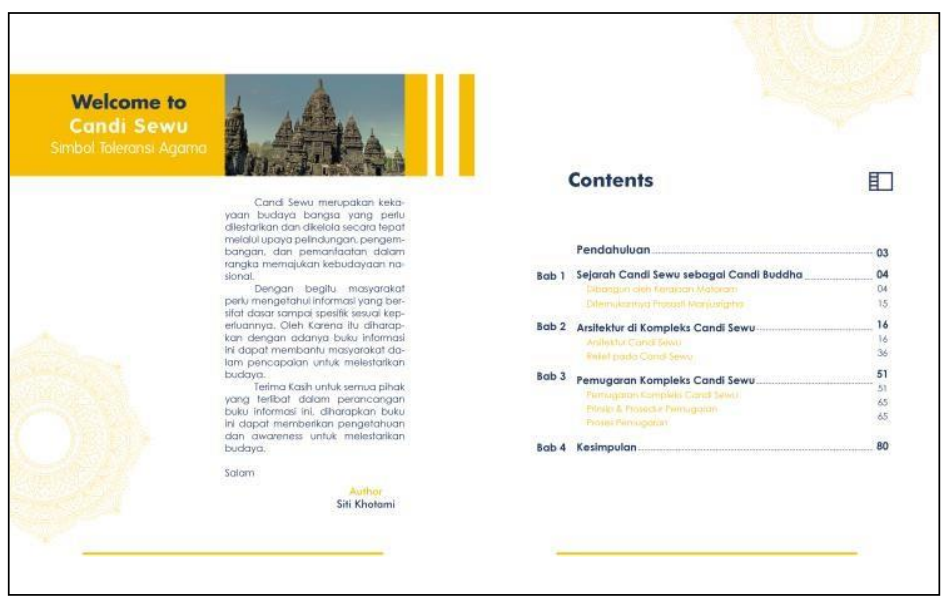

Gambar 15 Hasil Rancangan halaman buku

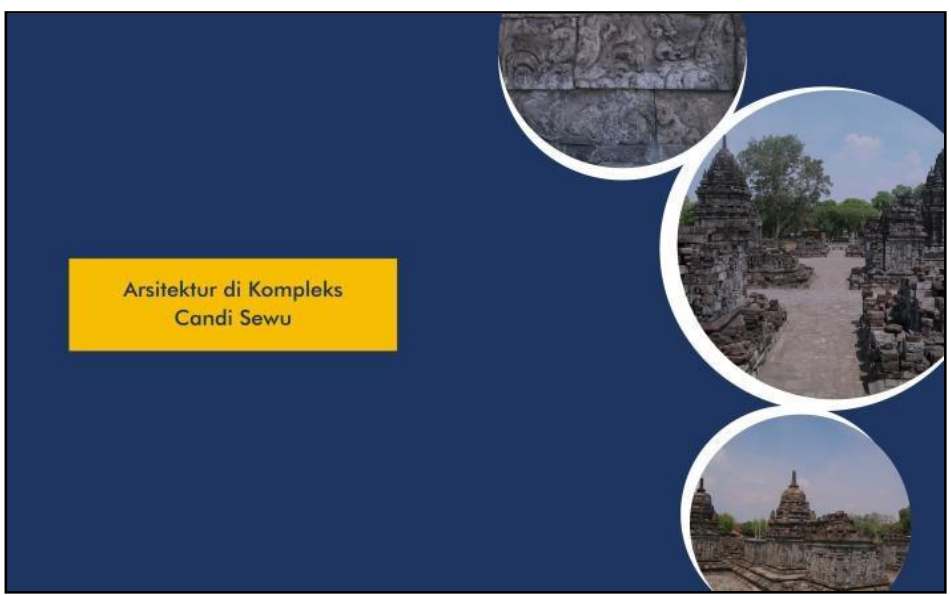

Gambar 16 Hasil Rancangan bagian bab buku

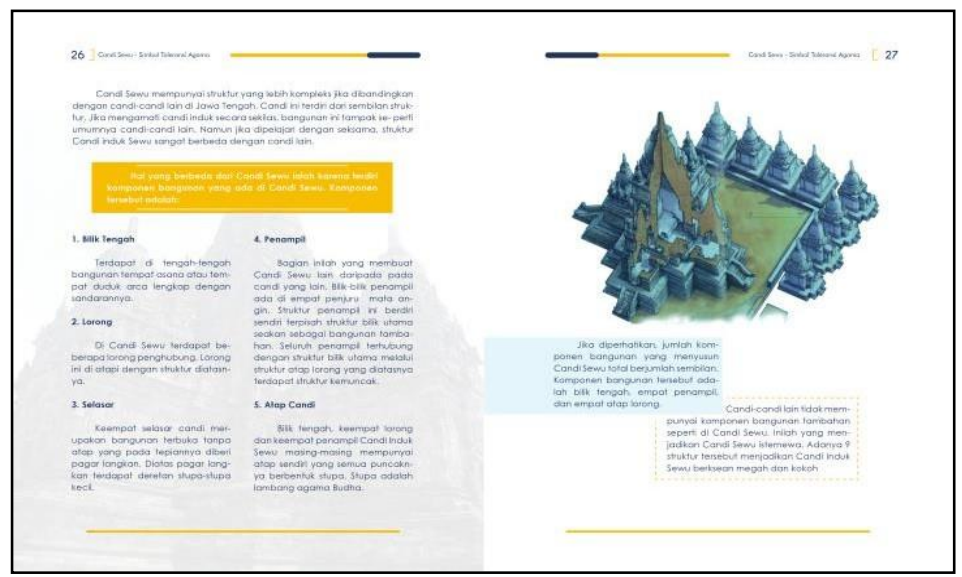

Gambar 17 Hasil Rancangan bagian isi buku 1 


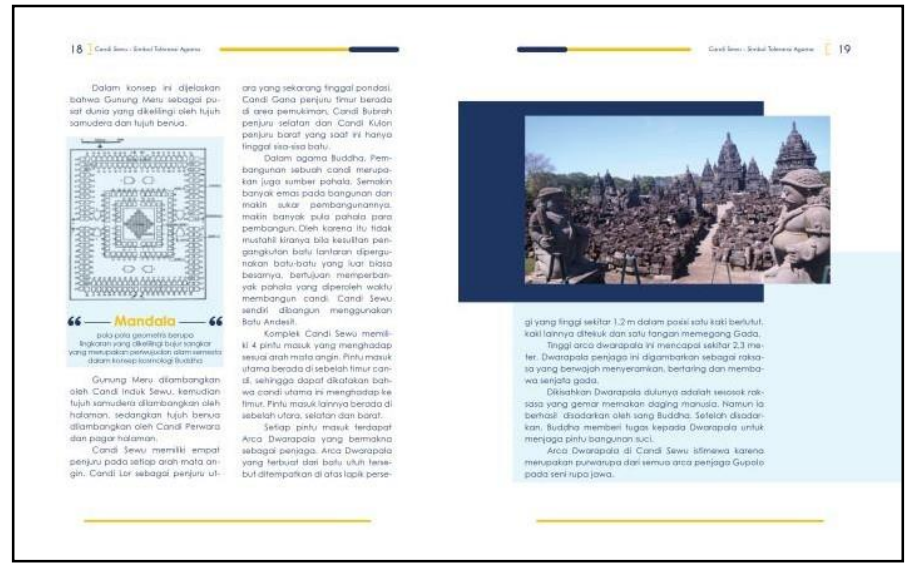

Gambar 18 Hasil Rancangan bagian isi buku 2

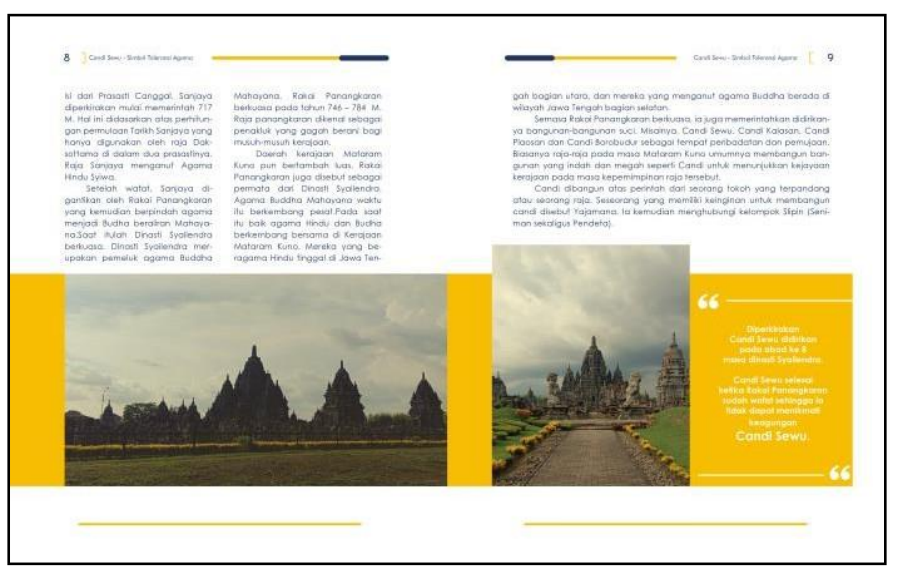

Gambar 19 Hasil Rancangan bagian isi buku 3

\section{SIMPULAN}

Candi Sewu merupakan Kompleks Candi Buddha terbesar di Indonesia. Hal tersebut masih belum diketahui banyak masyarakat karena beberapa kendala seperti bangunan candi yang belum utuh karena masih dilakukanpemugaran, media informasi yang menjelaskan Candi Sewu secara menyeluruh dan sebagainya. Oleh karena itu, dirancangnya media informasi berupa buku informasi mengenai Candi Sewu yang bertujuan untuk memudahkan masyarakat dalam memahami dan mengembangkan pengetahuan tentang Candi Sewu sehingga masyarakat bisa melestarikandan memanfaatkan Candi Sewu secara tepat.

Buku informasi yang dirancang berjudul Candi Sewu Simbol Toleransi Agama. Dalam buku ini memberikan informasi mengenai Candi Sewu secara menyeluruh dan terbagi menjadi empat bab, bab pertama berisi sejarah Candi Sewu sebagai Candi Buddha, bab kedua tentang arsitektur di kompleks Candi Sewu, bab ketiga mengenai pemugaran kompleks CandiSewu dan bab terakhir yaitu kesimpulan.

Buku informasi akan ditujukan untuk masyarakat wilayah Pulau Jawa khususnya Jogjakarta dengan usia 18-30 tahun yang menyukai ilmu arkeologi, arsitektur dan kebudayaan. Buku informasi Candi Sewu akan di publish ke perpustakaan nasional, perpustakaan daerah, perpustakaan pada perguruan tinggi dan sebagainya.

Sesuai dengan target khayalak yang telah ditentukan, buku informasi ini akan di rancang dengan konsep visual yang minimalis dan modern. Bukuini akan menggunakan warna tegas dan warna terang, jenis huruf san serif,ilustrasi yang banyak dipakai berupa foto. Pembahasan setiap informasi dibuat dengan kata-kata lebih sederhana agar mudah dipahami oleh masyarakat. 


\section{DAFTAR PUSTAKA}

Bungin, B. (2001). Metodologi penelitian sosial. Airlangga University Press.

Dameria, A. (2007). Color basic: Panduan dasar warna untuk desainer dan industri grafika. Link \& Match Graphic.

Dumacay, J. (2018). Candi Sewu et L'Architecture Bounddhique Du Centre De Java. École françaised'Extrême-Orient.

Infantyo, E., Ratnamulyani, I. A., \& Kusumadinata, A. A. (2017). Potensi pariwisata dan promosi Candi Sewu sebagai destinasi wisata bersejarah di Jawa Tengah. Jurnal Komunikatio, Vol. 3 (1), 29-36. https://ojs.unida.ac.id/index.php/JK/article/view/847

Istari, R. T. . (2015). Ragam hias candi-candi di Jawa. Kepel Press.

Kusrianto, A. (2009). Pengantar desain komunikasi visual. CV. Andi Offset.

Mahsyuri, \& Zainuddin, M. (2008). Metodelogi penelitian sosial dan ekonomi teori dan aplikasi. Alfabeta.

Murdihastomo, A. (2018). Dua tipe ornamentasi Candi Perwara di Kompleks Candi Sewu. KALPATARU Majalah Arkeologi, Vol. $27 \quad$ (2, 66-79. https://doi.org/https://doi.org/10.24832/kpt.v27i2.462

Sugiyono. (2012). Metode penelitian kuantitatif, kualitatif dan $R \& D$. Alfabeta. 